\title{
REGENERACIÓN EN LA DESEMBOCADURA DEL RÍO DOCE. EXPERIENCIAS Y COLABORACIONES EN EL CONTEXTO DEL DESASTRE EN LA COSTA NORTE DE ESPÍRITO SANTO, BRASIL
}

\author{
Regeneration at the mouth of the Doce River. \\ Experiences and collaborations in the context of the \\ disaster on the north coast of Espírito Santo, Brazil.
}

\author{
Bianca de Jesús Silva \\ Universidad Estatal de Campinas (Unicamp).Brasil.biancacsoufes@gmail.com
}

RESUMEN

El desastre en la cuenca del río Doce debido al colapso de la presa Fundão, tuvo lugar en 2015. Consecuencia de ello se liberaron 50 millones de metros cúbicos de relaves mineros. El material fluyó por el curso del río Doce hasta su desembocadura, ubicada en Regência Augusta, municipio de Linhares, estado de Espírito Santo. Dicho evento provocó incertidumbres y la aplicación de prohibiciones a la comunidad, especialmente con la pesca y el consumo de agua. De este modo se manifestaron diferentes formas de existir y hacer frente al contexto impuesto por el desastre. Este trabajo etnográfico se ha realizado entre los años 2015 y 2018, en Vila de Regência Augusta. Se estudian los cambios desarrollados en el contexto de desastre, teniendo como enfoque o hilo conductor a uno de los actores vinculados a la regeneración y sus alianzas con humanos y no-humanos. Los principales hallazgos arrojan que a partir del rescate ancestral, instancia en la cual se desarrollan nuevos vínculos con la tierra, como la alimentación y la curación con uso de plantas, se logra la promoción del cultivo, nuevas nociones del tiempo y nuevas formas de organización.

Palabras clave: río Doce; regeneración; regência Augusta; alianza; desastres

\section{ABSTRACT}

The disaster in the Doce river basin due to the collapse of the Fundão dam took place in 2015. As a result, 50 million cubic meters of mine tailings were released. The material flowed down the course of the Doce River to its mouth, located in Regência Augusta, municipality of Linhares, state of Espírito Santo. This event caused uncertainties and the application of prohibitions to the community, especially with fishing and water consumption. Thus, different ways of existing and coping with the context imposed by the disaster were manifested. This ethnographic work was conducted between 2015 and 2018, in Vila de Regência Augusta. It studies the changes developed in the disaster context, having as focus or thread one of the actors linked to regeneration and their alliances with humans and non-humans. The main findings show that from the ancestral rescue, an instance in which new links with the land are developed, such as food and healing with the use of plants, the promotion of cultivation, new notions of time and new forms of organization are achieved.

Key words: Rio Doce; regeneration; Regência Augusta; alliance; disasters

Recibido: 25 de marzo de 2021. Aceptado: 31 de mayo de 2021.

DOI: $10.32735 /$ S0719-5265202138330 


\section{Introducción}

Las discusiones sobre el desastre en la cuenca del río Doce se organizan en torno al escenario de destrucción, provocado por el derrame de relaves mineros de hierro, que fueron liberados por la ruptura de la presa Fundão, de la empresa Samarco y sus colaboradoras Vale y BHP Billiton (Losekann \& Mayorga, 2018).

Los relaves de la minera de hierro fueron depositados en los afluentes del río Doce y se transportaron por otros $600 \mathrm{~km}$ a lo largo de la cuenca hidrográfica, hasta el Oceano Pacífico, interrumpiendo varias formas de existir y relacionarse con el territorio cercano al río (Creado, Trigueiro \& Crizio, 2018).

A partir de esta coyuntura, se busca identificar las relaciones que se establecen en torno a la regeneración de la cuenca, enfocándonos en las dimensiones de resistencia y formas de organización en contextos alterados. Espećíiciamentebuscando

entre los fantasmas de la devastación que surgen en el contexto del antropoceno cabe, pues, dar con los enjambres de la vida, con los enredos, las imbricaciones, las mixturas o entaglements que sugieren los tipos de paisajes que pueden hospedar otras formas de vivir con/en/después de la devastación (Araos et al., 2019: 103).

Las impresiones sobre el desastre están relacionadas con la crítica hacia el modelo minero actual (Milanez, 2016), siendo las consecuencias de la ruptura de presas de relaves mineros, evidencias de los procesos de encuentro y desarrollo de relaciones entre diferentes seres, tanto humanos como no-humanos (Zhouri, 2018).

Las indicaciones contextuales descritas en este documento, son parte de las preocupaciones que surgieron durante una investigación desarrollada en el marco del programa de postgraduación en ciencias sociales de la Universidad Federal de Espirito Santo, enfocada en la desembocadura del río Doce, en Vila de Regência Augusta, entre los años 2015 y 2018 (Silva, 2018).

El objetivo del trabajo fue analizar las formas de conocimiento, a partir de nociones empírico-locales y tecnocientíficas relacionadas a las aguas, luego de la llegada de los relaves mineros. Destacando las disputas entre las condiciones del río y las aguas del mar. En este contexto, algunas experiencias de campo produjeron vínculos y preocupaciones relativas a las mudanzas que se estaban produciendo en la Vila de Regência (Mol, 1999).

Las experiencias basadas en la búsqueda de alternativas para sobrevivir en el contexto de desastre, que aquí se discuten, están relacionadas con la actuación del Coletivo Aliança Rio Doce. Este es un grupo formado a partir del llamado de Watu ${ }^{1}$ a la regeneración, estimulado a partir de la ruptura de la presa deFundão(Silva, 2019).

${ }^{1}$ Watu es el nombre que la ha dado al Río Doce el pueblo Krenak. El llamado de Watu se explica más adelante. 
La regeneración, llevada a cabo por el Colectivo, posee una perspectiva que va más allá del concepto de recuperación presentado por la Fundación Revona, vinculada a las empresas responsables de la rotura de la presa. Esta Fundación se creó con el objetivo de gestionar y ejecutar los programas encargados de "recuperar, mitigar, subsanar y/o reparar, incluyendo indemnizaciones para los afectados por el evento" (TTAC, 2016: 14). Los programas de Renova fueron principalmente de dos tipos y con diferentes impactos; programas socioeconómicos y socioambientales.

Por otro lado, el coletivo Aliança Rio Doce busca mirar el territorio y sus posibles relaciones, pretendiendo caminos libres del modelo con el que se establece la minería (De La Cadena, 2018),

O extrativismo se deparou com uma oposição implacável que articula, de maneira complexa e irregular, alianças inesperadas em demandas heterogêneas de uma vasta gama de coletivos. Centralmente e em toda a sua complexidade diversa, a aliança desafia o monopólio do Estado e das corporações a criar, habitar e definir a natureza - e, às vezes, o desafio que ela representa toca os nervos dos estados que produzem o sentimento de que a soberania sobre os territórios que governam é desafiada, e que suas esperanças de crescimento econômico (colocadas sobre o extrativismo) são comprometidas (De la Cadena, 2018: 105).

De esta forma, este artículo presenta las relaciones suscitadas y sus horizontes en torno al contexto de desastre. Lo anterior, es promovido a partir del diálogo establecido con uno de los integrantes de la Aliança Rio Doce, desarrollado durante las actividades de campo en 2015 y 2018, y retomado en 2020 mediante una entrevista. Dichas conversaciones abordaron la regeneración desde plataformas en línea, debido al contexto sanitario impuesto por la pandemia de COVID-19.

En las conversaciones en línea se abordó el proceso de cinco años, desde la ruptura de la presa, y las relaciones que surgieron en este contexto. Lo dicho, abarca el escenario económico y político actual, mostrando las expresiones de regeneración en la región de la desembocadura del Río Doce, como una forma de profundizar la recuperación ancestral.

La comprensión del contexto devastado se puede ampliar con las discusiones sobre los tiempos de catástrofe y las alternativas frente a las transformaciones observadas en el planeta (Stengers, 2015), que, en este caso, se profundizan ante la dimensión sensible de los procesos observados en la búsqueda de la regeneración.

Estos procesos serán analizados por la figura del barro y las relaciones que destruyó/produjo, enfocándose en el diálogo con uno de los afectados, destacando las relaciones de coproducción propuestas por Haraway (2015) y discusiones de 'entres' propuesto por Marras (2021). 


\section{Pensando el Antropoceno}

La discusión en torno a las dimensiones de los cambios observados en el planeta, considera la indicación de que los humanos están generando transformaciones aceleradas, que podrían demarcar una nueva era geológica. Esta ha sido denominada por Crutzen (2000) como Antropoceno. Este nombre, así como su expectativa de señalar los orígenes y el período en el que se inició, están presentes en la literatura correspondiente,

So, I think a big new name, actually more than one name, is warranted. Thus, Anthropocene, Plantationocene, and Capitalocene (Andreas Malm's and Jason Moore's term before it was mine). I also insist that we need a name for the dynamic ongoing sym-chthonic forces and powers of which people are a part, within which ongoingness is at stake. Maybe, but only maybe, and only with intense commitment and collaborative work and play with other terrans, flourishing for rich multispecies assemblages that include people will be possible (Haraway, 2015: 160).

Ante este debate, existe una fuerte idea de que, además de la clasificación, hay que entender que el Antropoceno compone un escenario actual, en el que se cuestiona la idea de crisis,

the time is past for hoping to "get through it." We are indeed, as they say, "in a tunnel," except that we won't see light at the end. In these matters, hope is a bad counselor, since we are not in a crisis. We can no longer say "this, too, will pass." We're going to have to get used to it. It's definitive (Latour,2017:13).

Debido al avance de algunos de los límites, entendidos como esenciales para mantener las condiciones ambientales necesarias para la continuidad de la vida humana (Rocktröm et al. 2009), se hacen cada vez más urgentes las acciones y respuestas, así como las formas de analizar la problemática ambiental a partir de un contexto de destrucción (Tsing, 2019).

Las dinámicas presentes en la construcción, mantenimiento, disrupción y despliegue de presas mineras de hierro, pueden dialogar con análisis que dinamizan las relaciones del Antropoceno. Un ejemplo de ello lo propone De La Cadena (2018), quien presenta las consecuencias ambientales de la explotación en los modelos de extracción vigentes en América Latina, así como las formas de resistencia presentes en los territorios que involucran moradores en disputa con grandes empresas, señalando los conflictos ontológicos presentes en este proceso.

La constitución de la problemática minera en el estado de Minas Gerais está fuertemente ligada a la historia de colonización y ocupación de espacios (Wanderley et al. 2016). Sin embargo, los avances en la explotación, el rápido aumento de 
tecnologías y la demanda por minerales, forman parte de otro aspecto de análisis que debe tenerse en cuenta: el escenario económico y político actual.

En este escenario, el fuerte avance de los gobiernos neoliberales, señalado por Wendy (2019), puede alinearse con las alteraciones y el modus operandi de las empresas responsables de los desastres (Rojas, 2017), así como con la forma de producir imaginarios y sujetos que complejizan las relaciones(Dardot\&Laval, 2016).

Estos elementos integran el Antropoceno entendido como el ámbito económico y político presente en el tiempo y espacio de los desastres.

La movilización de estos elementos ocurre ante la exposición de las resistencias observadas en parte del territorio afectado, que comprende una manifestación de particularidad, en la búsqueda de horizontes diferentes a los narrados por los debates en los que el colapso es inevitable (Gladwell, 2006).

\section{Desastre en la cuenca del Río Doce}

El desastre en la cuenca del Río Doce se ha abordado desde diferentes frentes disciplinarios en las universidades brasileñas, movimientos sociales y poblaciones afectadas, que presentan las consecuencias de la llegada de residuos mineros a los territorios ${ }^{2}$. Las formas de narrar las perspectivas sobre los desastres, y sus diversas formas de análisis, se entienden como una profundización del complejo contexto que se impone no solo por la disrupción, sino, por todos los procesos vinculados a la acumulación del modelo mineral, las relaciones políticas coloniales y las demandas económicas globales (Zonta, Cayres \& Souza, 2019).

Los indicios del desastre entendido como un proceso que necesita ser analizado antes, durante y después del colapso de las presas (Valencio, 2017), son parte de esta caracterización sobre la ruptura y sus consecuencias.

Se busca la caracterización del desastre a partir de los relatos y la experiencia que se acumula en los cinco años desde la ruptura, con énfasis en las entrevistas online realizadas en octubre de 2020 a uno de los vecinos de Regência, con quien se ha estado en contacto desde los primeros estudios de campo desarrollados en la región en 2015.

El interlocutor establece distintas relaciones con la región de la desembocadura del Río Doce. Una de ellas, propuesta por el interlocutor cuando se iniciaron los diálogos, corresponde a su identificación como 'surfista de la Regência'. Luego de los diversos encuentros y vínculos observados en las relaciones que formó

${ }^{2}$ Los grupos de estudio e investigación que se han mapeado como actores en los procesos de construcción de discusiones sobre el desastre en la cuenca del río Doce: Geppedes, Gepsa, Gesta, Organon, Poems, Criab, Rede Doce Mar, Nepo, así como la actuación de movimientos sociales con MAB, MAM y Caritas. 
en la región de la desembocadura del Río Doce, ahora se siente desautorizado o incapaz de señalar una categoría con la que se relaciona, y con la que puede definir sus vínculos.

Para el interlocutor, la caracterización del desastre del Río Doce, bautizado como Watu según la cosmovisión del pueblo Krenak, comenzó con las consecuencias que posibilitaron la organización de personas, las que despertaron al llamado de Watu. Según el entrevistado, el desastre no fue una sorpresa para el río, ya que, en las lecturas sobre los procesos y vigencias en el modelo minero adoptado en Brasil, (Zhouri et al. 2017), se comprendía que la disrupción ocurriría. Dada la certeza de la inminente ruptura, pero la incertidumbre del momento, Watu preparó a guerreros en cada generación, los que fueron convocados para resistir el desastre y recuperar el Río Doce tras la llegada de los desechos mineros.

El desastre era esperado por Watu, debido a la observación sobre los usos y la destrucción que se estaban llevando a cabo, commo señala Ailton Krenak (2019: 40),

O rio Doce, que nós, os Krenak, chamamos de Watu, nosso avô, é uma pessoa, não um recurso, como dizem os economistas. Ele não é algo de que alguém possa se apropriar; é uma parte da nossa construção como coletivo que habita um lugar específico, onde fomos gradualmente confinados pelo governo para podermos viver e reproduzir as nossas formas de organização (com toda essa pressão externa).

Estas uniones entre la experiencia del interlocutor y la literatura se vuelven interesantes, debido a la formación académica que posee en el área de Teología y Ciencias Sociales. A veces surge la pregunta ¿̇cómo observar lo que está planeando?, considerando que parte de la literatura que moviliza es conocida, por tanto, se vuelve necesario pensar cómo distinguir la literatura de la experiencia relatada. Ello, teniendo en cuenta que dicha duda retoma parte de la discusión elaborada en Marras (2018), sobre la complejidad del 'entre' cuando se discute 'entre' autores,

Daí aliás que, cada vez mais, aproximo a figura do intelectual profissional à figura do médium espírita ou à do cavalo ou burro da umbanda, por exemplo. Aproximação que visa tomar ambos, o médium e o douto, assim como o burro e o antropólogo, como mediadores de mundos heterogêneos. De fato, há aqui espíritos - que chamamos os Autores - que nos sopram e nos fazem dizer coisas, às vezes de modo mais direto, às vezes menos. Mas esses autoresespíritos também possuem e são possuídos por outros autores-espíritos, também eles respondendo a suas falanges, num encadeamento que torna todos nós mediadores de mediações, de modo que a reprodução de um pensamento, como vou desenhando aqui, possa assim se candidatar a prestar alguma contribuição, já que a tarefa da mediação, quando bem-sucedida, costuma agregar modificações, por sutis que sejam, e menos ou mais 
decisivas. Dizer isso (entredizer, portanto) é já o bastante para afirmar que o Eu que aqui fala se confunde, em boa medida, com um Nós (Marras, 2018: 252).

Así, se asume que la formación académica es uno de los elementos que componen los análisis, pero no el principal, y con ello, la idea de que el desastre precede a la ruptura se complejiza entre la literatura y la llamada de Watu.

Un aspecto importante para la caracterización del desastre tiene relación con la toma de decisiones, considerando que luego de la convocatoria de Watu hubo un período de duda. El relato de la aceptación de la llamada, resume la experiencia en la Caravana Territorial ${ }^{3}$, que tuvo como parte del programa un acto en el centro de la ciudad de Governador Valadares, en Minas Gerais. El interlocutor señaló que, durante la Caravana, a medida que conocían más sobre los tramos del río y los poderes impresos en él, iban dibujando de manera más definitiva las acciones para practicar el llamado de Watu. El interlocutor identificó el momento exacto en el que sintió que había aceptado el desafío de ser un guerrero del Río Doce.

Durante el acto en el centro de la ciudad, el Río se presentó con fuerza en una de las esquinas. Al acercarse a tal lugar, el interlocutor escuchó a uno de los compañeros de la manifestación cantar una canción sobre las aguas, y debido a la espontaneidad con que esta llegaba a sus oídos, junto con la fuerza que ejercía el Río en ese punto específico, definió que la llamada fue a partir de la escucha, y la aceptó.

Esta indicación retoma la idea de que la escucha se desarrolla como un elemento latente para los modernos (Marras, 2021). Aquí, el ejercicio contrario al rechazo de la escucha se entiende como una forma de iniciar el procesoderegeneración,

[...] Partícipes dessas cadeias de interdependência sensivelmente entrerrespondentes, os vegetais dão testemunho das suscetibilidades do Sistema Terra e também apontam para saídas de mitigação. Fornecem dados tanto sobre degradação quanto sobre regeneração. E, contudo, parece que os ouvidos modernos permanecem majoritariamente moucos. Insiste-se em enquadrar essas enormes, perigosas e tão ramificadas ocorrências na categoria de crise, a chama crise ecológica ou ambiental, sem que se dê conta (voluntariamente ou não) de que, como bem dia a filósofa Isabelle Stengers (2015:41), essa crise, diferente de qualquer outra, 'não é um momento ruim que vai passar' (Marras, 2021: 39).

3 La Caravana es un instrumento político-pedagógico construido por el movimiento agroecológico en Brasil, junto con diversas entidades, redes y movimientos sociales. Esta Caravana tuvo como propósito producir lecturas compartidas sobre la tragedia del crimen, analizar sus impactos, movilizar acciones de denuncias y reclamos, y señalar soluciones de desarrollo territorial más justas y sostenibles en la región. Disponible en: https://hase.org.br/pt/acervo/documentos/carta-politica-da-caravana-territorial-da-bacia-do-riodoce/. Último acceso: 24/10/2020. 
De esta manera, el desastre de la cuenca del Río Doce se puede caracterizar y analizar desde conflictos, cambios en las formas de vida, violaciones de derechos humanos, problemas aún no identificados en relación con la llegada de relaves, proporciones y mediaciones de la propagación de relaves, así como los niveles de contaminantes que pueden ocasionar diversos problemas a las regiones afectadas (Milanez; Losekann, 2016; Creado et al., 2017; UFES, 2017). Los análisis también pueden comprender los problemas político-económicos de la gestión minera en Brasil, las implicancias de la legislación y las formas de actuar en estos escenarios (Zorzal et al. 2019).

\section{Repensar el tiempo}

El parámetro tiempo está presente en las discusiones sobre el Antropoceno. Tanto como variable para presentar los cambios o como marcador de anuncios sobre límites y como elemento que acelera o ralentiza los procesos. El tiempo se señala como el período en el que se hizo posible la aceleración, a menudo recordada debido a las relaciones laborales en la revolución industrial. Y dada la importancia e insistencia del tiempo como instrumento para medir, cambiar y controlar, se busca señalar la importancia de los cambios en relación con el tiempo, como lo llama Latour (2017).

Uno de los episodios que llamó la atención sobre la forma en que se estaban discutiendo las nociones de regeneración, fue una conversación informal, en un desplazamiento en la Vila durante la actividad de campo en 2018. La conversación se basó en la noción de tiempo, la que se presentó como una búsqueda para trabajar de manera coherente con otras entidades que participaban en las actividades, mostrando procesos fuera de los ciclos del calendario que se organiza en horas, meses y años. Este cambio en la noción del tiempo, pone de manifiesto la aceptación de una demanda de transformación, en la que es posible decidir el momento de realizar las actividades, de acuerdo con las relaciones construidas con las entidades del pueblo.

La comprensión de los usos del tiempo, a partir de las relaciones con las entidades, reanuda las discusiones y las formas en que las etnografías clásicas movilizan el tiempo, como en el caso de Nuer (Evans-Pritchard, 1978). De esta manera, la regeneración también significa renunciar a los procesos que componen el cuerpo de los desastres, a la vista de la lógica del tiempo del mercado, la rapidez con la que se hace y así se olvida.

Asimismo, se evidenció la importancia del tiempo para la construcción de la regeneración, siendo esta aprehendida por el Coletivo Aliança Rio Doce a partir de 
la relación con las entidades que presentan otras dimensiones y nociones de temporalidad en el territorio.

\section{Conociendo la regeneración}

Al participar en algunos eventos organizados por el Coletivo Aliança Rio Doce, se comenzó a delinear la comprensión de la regeneración en la que trabajaban.

Los primeros elementos que se entendieron como una de las dimensiones de la regeneración fueron las actividades de permacultura, considerando que uno de los pilares de esta actividad se llama regeneración (Mollison \& Slay, 1998). Por otra parte, se participó del Segundo Encuentro de Cultura Ancestral, realizado en noviembre de 2017, instancia que fue diseñada para reunir a diversos actores de la cuenca del Río Doce en torno a la regeneración de la ascendencia.

En el evento se llevaron a cabo diversas actividades y debates sobre formas de resistir y regenerar la cuenca del Río Doce. Entre ellas, se destacan tres momentos en los que fue posible reflexionar sobre la expansión del concepto de regeneración. Es importante hacer notar que la idea de permacultura, se agrega a la perspectiva en que se expresa el territorio de la región de la desembocadura del Río Doce, de modo material e inmaterial.

El primero de estos momentos, fue el intercambio de semillas criollas, en el que las semillas representaban la posibilidad de regeneración de la tierra y encuentro con los orígenes de los alimentos. El segundo episodio fue la quema de alfarería, en la que ésta representaba una forma de expresión del territorio. El episodio de la cerámica es interesante dada su vinculación con el tercer elemento que compone el horizonte de regeneración percibido en ese momento, relacionado a la almescla. Durante la cocción de la cerámica, uno de los representantes del pueblo Krenak expresó el deseo de quemar almescla, una resina utilizada para diversos fines ${ }^{4}$, pero que en ese momento estaba siendo empleanda para componer un humo tradicional (Silva, 2019).

Los tres momentos, configuran el entendimiento acerca de la regeneración e incorporan a la tierra, con el presente, pasado y futuro. El intercambio de semillas expandió el territorio, a partir de semillas que llegaban y semillas que salían, concretándose en estos intercambios la idea de la cuenca. La quema de cerámica apuntaba al rescate del pasado, la mediación con el presente en la expectativa de enseñar a los niños y la búsqueda de esas prácticas en la memoria de los adultos. La

${ }^{4}$ Los usos de almescla fueron sistematizados durante la actividad investigadora del grupo Río Doce Mar. Disponible en: https://www.comriocommar.com.br/blog/chamada-ciclo-da-aroeira-eda-almescla. Último acceso: 24/10/2020. 
cosecha de almescla, representaba el futuro y las relaciones, pues durante la cosecha se había firmado el compromiso de una próxima cosecha.

\subsection{Aliados}

Presentar los aliados es señalar las relaciones que se han construido durante los cinco años transcurridos desde la ruptura. En este tiempo la forma de asociarse consideró la expresión de la comunicación entre las entidades como un direccionamiento para la regeneración. Algunas de las relaciones presentadas por el interlocutor también fueron tratadas en Creado (2020), lo que refuerza su potencial. Las relaciones también son consideradas en vista de la capacidad de las asociaciones para narrar resistencias frente a procesos hegemónicos.

Lenguaje y aprendizaje fueron las palabras más frecuentes para caracterizar las relaciones con las personas, y fueron sistematizadas como un cúmulo de experimentación con la comunicación basada en el afecto entre humanos. Se entiende que la experiencia es la forma de comunicarse y vivir el mundo de otras formas, y a un ritmo diferente, ello permitió a los integrantes de la alianza Río Doce (Silva, 2019), especialmente a su lider que habla directamente en este texto, comunicarse con entidades diferentes, y así continuar en la construcción colectiva de la regeneración.

Las conversaciones online recuperan las discusiones sobre las entidades. En este sentido, se empezaron a incorporar cangrejos, serpientes, plantas, flores, raíces, savia y, finalmente, la tierra y el retorno a ella (Latour, 2014). Las relaciones de las entidades se tejen a partir de la feria, espacio que promueve el encuentro de las entidades y sus expresiones como aporte a la regeneración.

La feria se presentó como un espacio de intercambio para las formas de expresión de regeneración producidas en el territorio. También se está entendiendo como una forma de ampliar el alcance de los intercambios con las entidades, ya que, la exhibición de los productos y la circulación de personas, se entiende como una forma de expandir y/o iniciar los procesos de curación en el pueblo.

La feria tiene espacio en la estructura de Tamar ${ }^{5}$. La construcción de la feria se basa en la perspectiva de cero residuos. Esta perspectiva se utiliza en todos los espacios llevados a cabo por la Aliança Rio Doce, considerando que el cuidado con la disposición es un aspecto de la regeneración, involucrando el compostaje como un instrumento para potenciar las actividades con la tierra. Y así, todas las actividades y productos de la feria de Vila Mágica, están afrontando relaciones con la regeneración, que según la divulgación de la feria son: hierbas medicinales, buena

5 Disponible en: https://www.tamar.org.br/centros_visitados.php?cod=5. Último acceso: $24 / 10 / 2020$. 
música, buena comida, cerveza artesanal, plantas suculentas, crochet, gorros, ropa y otras producciones de tipo cultural.

Las expresiones de regeneración presentadas en la feria se señalarán a partir de los vínculos y formas que configuran la idea de regeneración. La elaboración de cerveza, crochet y gorras juega un papel en el proyecto de regeneración, siendo las gorras las encargadas de dar a conocer la Vila y las actividades que allí se desarrollan, ya que son estampadas con las olas de Regência y otros símbolos como el Faro de Regência. El crochet se establece al mismo tiempo que se elimina el consumo y la producción de prendas industriales, promoviendo una opción libre de petróleo. Y las cervezas se elaboran a partir de plantas, como la aroeira (Schinus terebinthifolius), siendo otra forma de exponer sus características curativas.

Las hierbas medicinales, la buena comida y música son aspectos vinculados a la dimensión de la búsqueda ancestral y los usos de estas expresiones. Las hierbas medicinales se elaboraron a partir de la conversación con las plantas y la forma en que el territorio las presenta para su regeneración, especialmente los aceites esenciales de aroeira. Éste fue presentado por el interlocutor como un instrumento de curación dadas las propiedades de la planta y el aumento de esta especie en la Vila, instancia que llegó a entenderse como el anuncio sobre aquello que se debe curar y el modo en que debe hacerlo

Ante la prohibición de la pesca y los problemas que han surgido a partir de este escenario, la buena comida dialoga con la idea de comida afectiva y la búsqueda de alimentos libres de contaminación, (Silva \& Torres, 2018). Así, la inserción de vegetales en moquecas ${ }^{6}$, también se presenta como una alternativa a los impedimentos creados por los residuos mineros. De esta manera, se consideraron otras formas de comer, no solo en relación con los ingredientes, sino también pensando en las preparaciones, en cuyo caso se destacan los panes de fermentación natural más lunación específica como un elemento característico de su cocina.

La buena música es fruto del trabajo realizado en la casa de cultura Casa Rosa, en el que un proyecto musical para jóvenes dio origen a la banda Natividade, compuesta por jóvenes de la Vila que buscan cuidar su lugar de origen. Las ASF, abejas sin aguijón (del portugués, Abelhas Sem Ferrão), exhiben la miel del apicultor y los beneficios del cultivo de abejas, desde la producción de miel para consumo y/o comercialización. Estos se encuentran insertados en la perspectiva de la regeneración, incorporando narrativas sobre beneficios para la salud mental, logrados con el cuidado y contacto con las abejas y la contribución a la diversidad ecológica, teniendo en cuenta la actividad polinizadora.

${ }^{6}$ Comida típica del estado de Espírito Santo donde la preparación utiliza pescado como ingrediente principal. Disponível em: https://www.es.gov.br/cultura/culinaria-capixaba. Último acesso em: 15/10/2020. 
El colectivo Ceramística ofrece la cerámica producida a la luz del conocimiento que se expresa en el rescate de la cerámica Areal, y por el conocimiento previo de las personas involucradas que comprenden la realización y materialización de la tierra en formas y figuras. La producción de cerámica permite la imaginería de los seres, como la serpiente, que sintetiza la apertura de caminos, el contacto con la tierra y el trabajo sobre el territorio.

Se o mundo for
de fato
um pote
nós somos as bordas.
Giramos, uma para a direita
a outra para a esquerda,
enroscadas no Afeto
que mantém o fino
equilíbrio do Planeta.
Serpente vai
Serpente vem
neste Grande Pote
que nos contém ${ }^{7}$

La noción de vasijas se entiende como una metáfora sobre la necesidad de aprehender la regeneración, dado el entendimiento de que la cantidad de información y sentimiento que llena a los individuos los deja sin lugar para sentir y comprender los espacios que ocupan (Stengers, 2011).

Las macetas son posibilidades para reponerse de energía y conocimientos con los que la comunicación con los espacios se vuelve posible y poderosa, dada la estrategia de estar atento a lo que se coloca dentro de ellas. La alfarería profundiza las relaciones con las plantas a partir del uso de macetas para el cultivo, pero también está la producción de otros elementos como teteras y difusores de aromaterapia.

La producción de cerámica está vinculada a la construcción y uso del horno. La propia producción del horno expresa la autonomía y la relación con el fuego. Este aspecto aparece en publicaciones en redes sociales ${ }^{8}$ que apuntan a la construcción

7 Disponible en: http://www.instagram.com/p/B6oiHjyhnlq/. Último acceso: 24/10/2020.

${ }^{8}$ Disponible en: https://www.instagram.com/coletivo_ceramistica/?hl=pt-br. Último acceso: $24 / 10 / 2020$. 
del horno como un desafío, en vista de las especificidades que se imprimen para lograr el proceso de quemado. Además, este ritual se identifica como parte de la relación de aprendizaje con las entidades dispuestas en el territorio, ya que en la completitud de la cerámica se observan los cuatro elementos: tierra, fuego, aguay aire.

Las alianzas y el aprendizaje con los seres queridos se destacan como instrumentos para buscar otras expresiones de vida en la Vila, en el sentido de que estos procesos han surgido en los últimos cinco años, pero están abiertos a expandir la regeneración, y así resistir y organizarse en el entorno impuesto por el vertido de relaves en las aguas del río Doce y el océano Atlántico. En este proceso, es evidente que, además de las formas de componer y dividir espacios que están abiertos a la regeneración, esta narrativa busca remover de manera política otros problemas que se están desenvolviendo desde el desastre, y que serán narrados desde la creación y articulación de espacios institucionales.

\subsection{Relaciones}

Luego de cinco años de desastre, las alianzas, encuentros, intercambios, métodos de aprendizaje y lenguajes que se establecieron, y están presentes en el territorio, narran los períodos desde la llegada del barro y cómo se está practicando el mantenimiento de Watu.

La forma de establecer relaciones con el territorio devastado pasa por la perspectiva que fue presentada, en que los elementos están en relación y son comprendidos en cuanto entes que expresan y presentan los caminos de la regeneración, en ocasiones propiciando la sanación, mejorando la comunicación, abren los caminos de los afectos y crean alternativas para las experiencias en el territorio alterado por el desastre en la cuenca del río Doce.

La llegada de los relaves profundiza el diálogo y el entendimiento que la comunicación se lleva a cabo entre seres, tanto humanos como no-humanos, tal como los presenta el interlocutor, y que estos procesos, una vez iniciados, son potentes y de comunicación abierta a cualquier entidad, persona y elemento. $\mathrm{Y}$ en este proceso de profundización, los estudios sobre arsénico, hierro y cadmio están en marcha por parte del interlocutor y en el horizonte de actividades, que se realizan en la región de la desembocadura del Río Doce, con la premisa de una posible comunicación entre todas las entidades que están en relación.

La comunicación se convierte entonces en el aspecto más importante y fundamental de las relaciones de regeneración, ya que solo a través de ella serán posibles los procesos de curación y comprensión de los espacios que se ocupan y del modo en que se pueden vivir de la mejor manera. Durante los cinco años, la comunicación promovió una articulación entre humanos y no-humanos y regresó como una articulación para mejorar la comunicación entre los primeros, en forma 
de alianzas políticas en el territorio. La realización de la feria, eventos, como el encuentro de la cultura ancestral en Areal y los intercambios culturales que tuvieron lugar después de la rotura de la represa de Fundão, son indicios sobre esta circulación del conocimiento de la regeneración como instrumento, pero también como proceso de organizaciones políticas, como la constitución de Asociaciones, la creación del Foro Norte de Foz do Rio Doce ${ }^{9}$ y también la creación de la asociación de surf de Regência.

Las ideas sobre las transformaciones de plantas y animales se pueden explorar tanto en términos de literatura como de relaciones producidas en la Vila. Ante la ausencia de continuidad en el trabajo de campo, se buscó ampliar las discusiones a partir de las relaciones con las aguas, en vista de la trayectoria que toca a este trabajo. Las relaciones con las aguas es una de las primeras del interlocutor con la Vila, pues, inició su trayectoria de regeneración como surfista.

A partir de la discusión con el interlocutor, se entiende que las nociones acerca de acceso al surf están generando cambios en la Vila, ya que se comprende que antes del desastre, quienes buscaban la aldea para surfear, mantuvieron las relaciones que encontraron allí en forma más sistemática. El mantenimiento se observa en base al cuidado del agua, las olas, las personas que hacen posible la actividad, en el sentido de contacto con la gente de las posadas, y con la comida. Estos elementos, que caracterizan el cuidado que expresa el surf, han sido amenazados por procesos señalados por el interlocutor como modernización.

Las regeneraciones en las aguas tienen aspectos interesantes para observar, teniendo en cuenta los vínculos del surf, pero también entendiendo a las aguas como elementos que fueron impactados de modo inicial en la región, en el Océano Atlántico y a otras regiones, se fromaron nuevos aspectos del desastre hacia otros contextos.

Las aguas se manifiestan de forma sistemática, recordando y reviviendo el desastre, presentando la demanda de cambio siempre que se agita en sí mismo. Las lluvias son las responsables del recordatorio visual del desastre, agitando los relaves que se depositaron en el fondo del río Doce y en el Océano Atlántico. La comunicación con entidades de la región de la desembocadura del Río Doce, se presenta como una forma de cooperación, en la que los sujetos se van organizando, acercándose y aprendiendo de los procesos de curación. Mientras tanto, las aguas siguen recordando el desastre, dejando la demanda de cambio no solo en la Vila. Los anuncios de que el modelo actual ya no es viable se pueden repensar a partir de diferentes contextos destruidos por las mismas fuerzas que provocaron el desastre en la cuenca del Río Doce.

${ }_{9}$ Disponible en: https://www.seculodiario.com.br/meio-ambiente/comunidades-ao-norteda-foz-do-rio-doce-articulam-criacao-de-forum-dos-atingidos. Último acceso: 24/10/2020. 
La comunicación del agua se encarga de mantener relaciones basadas en la constante manifestación de afecto, las posibles uniones entre las entidades, la necesidad de mirar el entorno y comprender lo que está afuera y adentro. Es el medio que anuncia y resalta la necesidad de comunicarse y, así, recordar la necesidad de estas otras alianzas. "Por ora, quero sublinhar que cada vez mais - e nisso, insisto, funda-se uma aposta - viver mostra-se urgentemente como entreviver. Existir como coexistir. Evoluir como coevoluir. Morrer como entremorrer. Reagir como entrerreagir." (Marras, 2018: 256).

\section{Consideraciones finales}

Vila Mágica es un proyecto. El territorio aún está lleno de conflictos y obstáculos, estos preceden incluso a la llegada de relaves mineros, ya que los conflictos con grandes proyectos (Leonardo, 2014) ya estaban en curso, debido a la figura de Petrobras y los conflictos sociotécnicos con el proyecto Tamar(Fontinelli, 2016).

La llegada de los relaves también trae a la Vila los problemas relacionados con el desenlace del desastre, siendo estos diversos, como las relaciones de género, el fomento de la divergencia en la comunidad a través de empresas, las formas de gestión del dinero de las ayudas e indemnizaciones (Zhouri et. al., 2018).

Las entidades se activan, se comprenden, se juntan, hacia la ascendencia, pero también están siendo el recordatorio de que hay otro u otros caminos, y que el que desgasta, destruye, desfigura y transforma no solo a los seres, sino las personas y las relaciones entre ellas, ya no puede ser una alternativa. De esta forma, reflexionar respecto de las acciones gestadas en la región de la desembocadura del Río Doce, a partir del acompañamiento de la experiencia y trayectoria de uno de los múltiples sujetos envueltos en el proceso, evidencia las demandas y complejidades que emergieron después de la llegada de los desechos de la minería de hierro. Asimismo, se presenta un escenario que comprende ruinas y busca relaciones con el territorio y con los entes que están presentes en él, apuntando para las formas de expresión, comunicación y potencias en la narrativa que dirige los caminos de la regeneración para la Vila de Regência Augusta.

\section{Referencias}

Araos, F., Riquelme, W., Skewes, J. C., Vianna, A., Alvarez, R., Ther, F., Iwama, A., Albagli, S., Costa, A. \& Duarte,. E. (2019). La vida después de la devastación. Antropologías del Sur. (6)12, 87-106.

Bronw, W. (2019). Nas ruínas do neoliberalismo: A ascensão da política antidemocrática no Ocidente. São Paulo: Politeia. 
Cadena, M. de la. (2018). Natureza incomum: histórias do antropo-cego. Revista Do Instituto De Estudos Brasileiros, (69), 95-117.

Creado, E. (2020). Mine tailings and enviromental (dis)controls in a Brazilian coastal área. Brasilia: Toxic News.

Creado, E. S. J., \& Helmreich, S. (2018). Uma onda de lama: viagem de águas tóxicas, de Bento Rodrigues ao Atlântico brasileiro. Revista do Instituto de Estudos Brasileiros, (69), 33-51.

Creado, E., Trigueiro, A. \& Torres, C. (2018) Vidas de rio e de mar: pesca, desenvolvimentismo e ambientalização. 1. ed. - Vitória: ProEx, 2018.

Das, V. (1995). Critical events: an anthropological perspective on contemporary India (Vol. 7). Delhi: Oxford University Press.

De Araújo Torres, C. C., Creado, E. S. J., Campos, A. C., \& de Freitas, P. L. T. (2017). Repertórios em rede: o caso da mobilização de duas espécies de tartarugas marinhas em uma ação civil pública $1 /$ repertoires in network: the case of a civil public action devoted to protect two seaturtles species. Vivência: Revista de Antropologia, 1(49), 75-96.

Evans-Pritchard, E. (1978). Os Nuer. São Paulo: Perspectiva.

Ferreira, L. D. C. (2004). Dimensões humanas da biodiversidade: mudanças sociais e conflitos em torno de áreas protegidas no Vale do Ribeira, SP, Brasil. Ambiente \& sociedade, 7(1), 47-66.

Fontinelli, D. (2016). Santa Tartaruga! Invenções e mudanças ontológicas no litoral norte do Espírito Santo. (Master's thesis, Universidade Federal do Espírito Santo).

Fontinelli, D. S., \& Creado, E. S. J. (2020). From food to offspring: engagement between humans and sea turtles in two communities on the north coast of Espírito Santo. Vibrant: Virtual Brazilian Anthropology 17, 1-20.

Gladwell, M. (2006). The tipping point: How little things can make a big difference. New York: Little, Brown.

Haraway, D. (2015). Anthropocene, capitalocene, plantationocene, chthulucene: Making kin. Environmental humanities, 6(1), 159-165.

Haraway, D. J. (2016). Staying with the trouble: Making kin in the Chthulucene. Durham: Duke University Press.

Ingold, T. (2015). Estar vivo: ensaios sobre movimento, conhecimento e descrição. Petrópolis: Editora Vozes Limitada.

Kossoff, D., Dubbin, W. E., Alfredsson, M., Edwards, S. J., Macklin, M. G., \& HudsonEdwards, K. A. (2014). Mine tailings dams: Characteristics, failure, environmental impacts, and remediation. Applied Geochemistry, 51, 229-245.

Krenak, A. (2019). Ideias para adiar o fim do mundo. São Paulo: Editora Companhia das Letras. 
Latour, B. (2014). Para distinguir amigos e inimigos no tempo do Antropoceno. Revista de Antropologia, 57(1), 11-31.

Latour, B. (2017). Facing Gaia: Eight lectures on the new climatic regime. Cambridge: Polity

Latour, B. (2020). Diante de Gaia: Oito conferências sobre a natureza no Antropoceno. São Paulo: Ubu Editora.

Laval, C., \& Dardot, P. (2016). A nova razão do mundo: ensaio sobre a sociedade neoliberal. São Paulo: Boitempo.

Leonardo, F. A. M. (2014). Entre o desenvolvimento econômico e a preservação ambiental: O Caso da Pesca Artesanal e a Configuração de um Cenário de Injustiça Ambiental em Regência Augusta-ES. Dissertação de mestrado, Programa de Pós-Graduação em Ciências Sociais. Vitória, ES: UFES).

Losekann, C., \& Mayorga, C. (2018). Desastre na Bacia do Rio Doce. Desafios para a universidade e e e para instituições estatais. Rio de Janeiro: Folio Digital: Letra e Imagem.

Marras, S. (2021) O vozerio da pós-verdade e suas ameaças civilizacionais Stelio Marras, in: De Oliveira, J., Amoroso, M., Morim Da lima, A., Shiraton, K., Marras, S. \& Emperaire, L. (Ed.). Vozes vegetais: Diversidade, resistência e histórias da floresta. São Paulo: Ubu Editora.

Milanez, B., \& Losekann, C. (2016). Desastre no Vale do Rio Doce: antecedentes, impactos e ações sobre a destruição. Rio de Janeiro: Letra e Imagem Editora e Produções LTDA.

Miranda, M. G., Friede, R., Rodrigues, A. C., \& Almeida, D. S. (2017). Cadê a minha cidade, ou o impacto da tragédia da Samarco na vida dos moradores de Bento Rodrigues. Interações (Campo Grande), 18(2), 3-12.

Mol, A. (2008). Política ontológica: algumas ideias e várias perguntas. Objectos impuros: experiências em estudos sobre a ciência. Porto: Afrontamento, 63-106.

Mollison, B., \& Slay, R. M. (1998). Introdução à permacultura. Brasília: MA/SDR/PNFC.

Oliver-Smith, A., \& Hoffman, S. M. (Eds.). (2019). The angry earth: disaster in anthropological perspective. Londres: Routledge.

Rockström, J., Steffen, W., Noone, K., Persson, Å., Chapin, F. S., Lambin, E. F., ... \& Nykvist, B. (2009). A safe operating space for humanity. Nature, 461(7263), 472-475.

Rojas, C. M. O., \& Pereira, D. B. (2018). As veias continuam abertas: o rompimento da barragem de Fundão/MG e o modus operandi da Samarco (Vale/BHP Billiton). Lutas Sociais, 22(41), 223-236.

Silva, B. (2018). "A lama que rolou de cima": Alguns desdobramentos sociopoliticos e sociotécnicos sobre as águas do rio doce e do oceano atlântico na região da foz, após o rompimento da barragem de fundão-MG. (Master's thesis, Universidade Federal do Espírito Santo). 
Silva, B. (2019). Coletivo Aliança rio Doce - Convivencialidade e Regeneração no Desastre na Bacia do rio Doce. In: IX Encontro Associação Nacional De Pós-graduação E Pesquisa Em Ambiente E Sociedade, 2019, Brasília. Anais Completos do IX Encontro Nacional da ANPPAS, 2019. p. 1070-1084.

Stengers, I. (2015). No tempo das catástrofes. São Paulo: Cosac Naify, 71.

Taddei, R. (2015). O lugar do saber local (sobre ambiente e desastres). Siqueira, A.; Valencio, N.; Siena, M. Rima, v. 1, p. 311- 327.

Tsing, A. (2019). Viver nas ruínas: paisagens multiespécies no Antropoceno. Brasília: IEB Mil Folhas.

TTAC (Termo de Transação e de Ajustamento de Conduta) (2016, 2 marzo). Dispõem sobre acordo entre o Governo Federal, Governo do estado de Minas Gerais, Governo do estado Espírito Santo e as mineradoras Samarco Mineração S/A, Vale S/A e BHP Billiton Brasil Ltda. Brasília, 2016. Disponível em: http://ibama.gov.br/cif/cif-comiteinterfederativo. Acesso em: 09 fev. 2021

UFES (2017). Monitoramento da influência da Pluma do Rio Doce após o rompimento da Barragem de Rejeitos em Mariana/MG - novembro de 2015: Processamento, Interpretação e Consolidação de Dados.

Valencio, N. (2017). A ordem invisível por detrás do caos aparente: arquitetura do poder e desfiliação social no contexto de desastre. ENCONTRO ANUAL DA ANPOCS, 41.

Wanderley, L. J., Mansur, M., Milanez, B. \& Pinto, R. (2016). Desastre da Samarco/Vale/BHP no Vale do Rio Doce: aspectos econômicos, políticos e socioambientais. Cienc. Cult., São Paulo, (68) 3, 30-35.

Zhouri, A., Oliveira, R., Zucarelli, M., \& Vasconcelos, M. (2017). The Rio Doce Mining Disaster in Brazil: between policies of reparation and the politics of affectations. Vibrant: Virtual Brazilian Anthropology.

Zorzal, M., Cayres, D. C., \& Souza, L. A. M. (2019). Desastre socioambiental e Termo de Transação e Ajustamento de Conduta (TTAC) como instrumento de política pública: o caso da barragem de Fundão, MG. Civitas-Revista de Ciências Sociais, 19(2), 464488. 